\title{
Ethics, law, and politics in palaeontological research: The case of Myanmar amber
}

Emma M. Dunne (dunne.emma.m@gmail.com; @emmadnn), Nussaïbah B. Raja (nussaibah.raja.schoob@fau.de; @ mauritiantales), Paul P. Stewens, Zin Maung Maung Thein and Khin Zaw

This manuscript has now been peer-reviewed and published in Communications Biology. Please use the following citation:

Dunne, E.M., Raja, N.B., Stewens, P.P., Zin Maung Maung Thein, Khin Zaw (2022) Ethics, law, and politics in palaeontological research: The case of Myanmar amber. Commun Biol 5, 1023. https://doi.org/10.1038/s42003-022-03847-2

Previous versions of this manuscript on this server may have slightly different content. Please feel free to contact us if you have any queries or comments; we welcome all feedback. 


\title{
Ethics, law, and politics in palaeontological research: The case of Myanmar amber
}

\author{
Emma M. Dunne ${ }^{1,2, *, \mathbb{}}$, Nussaïbah B. Raja ${ }^{1 *}$, Paul P. Stewens ${ }^{3}$, Zin Maung Maung Thein ${ }^{4}$, and Khin Zaw ${ }^{5}$ \\ ${ }^{1}$ GeoZentrum Nordbayern, Friedrich-Alexander University Erlangen-Nürnberg, 90154 Erlangen, Germany \\ ${ }^{2}$ School of Geography, Earth and Environmental Sciences, University of Birmingham, Edgbaston, Birmingham, UK \\ ${ }^{3}$ Department of International Law, Geneva Graduate Institute, Chemin Eugène-Rigot 2A, Geneva CH-1211, Switzerland \\ ${ }^{4}$ Department of Geology, University of Mandalay, Mahaaungmyae 05032, Mandalay, Myanmar \\ ${ }^{5}$ CODES Centre of Ore Deposit and Earth Sciences, School of Natural Sciences, University of Tasmania, Geology Building, Clark Rd, Private Bag 79, Hobart, TAS 7001, \\ Australia \\ *These authors contributed equally to this manuscript.
}

Fossil material in amber from Myanmar can provide important insights into mid-Cretaceous forest ecosystems. However, Myanmar amber has been receiving increased international attention due to reported links between amber mining and the ongoing humanitarian crisis in northern Myanmar, as well as the legal issues associated with its exportation. Here, we conduct a bibliometric analysis of Myanmar amber publications (1990-2021) and demon- strate how research interest in Myanmar amber is explicitly linked to major political, legal, and economic changes. An analysis of the authorship networks for publications on amber inclusions reveals how current research practices have excluded Myanmar researchers from the field. In addition, the international trade of Myanmar amber with fossil inclusions falls into a legal 'grey-zone' which continues to be exploited. This case study vividly demonstrates that systemic changes, alongside an increased awareness of inequitable research practices amongst the broader scientific and allied communities, are urgently needed to curb illegal practices in palaeontology.

palaeontology | Myanmar amber | parachute science | research ethics | scientometrics

Correspondence: dunne.emma.m@gmail.com

\section{Introduction}

Fossils entombed in amber provide exceptional and unique insights into the morphology and evolution of organisms that inhabited past forest ecosystems (1). Amber, which is fossilised plant resin, of various geological ages can be found in several parts of the world, including the Baltic region of Europe, Alaska, Madagascar, Lebanon, the Dominican Republic, and Canada. Amber from Myanmar (Burma) is particularly famous for preserving the remains of insects, plants, and reptiles that lived alongside the dinosaurs during the midCretaceous, approximately 99 million years ago (2). However, Myanmar amber has more recently gained international attention due to legal and ethical issues in the discovery, collection, trade, and research of this material (3-5).

Myanmar has a rich palaeontological heritage, including fossils of the oldest representatives of anthropoid primates (6). But by far the most popular fossil finds from the country are those in amber. Most amber is mined in the northern state of Kachin, with many fossils coming from the Hukawng Valley (Fig. 1). To the international palaeontological community, this region is highly productive in terms of amber fossils, but on the ground, it has endured armed conflict between the Kachin Independence Army (KIA) and the Myanmar government military forces, the Tatmadaw, since the 1960s, only two decades after the country gained independence from British rule in 1948. Both the KIA and the Myanmar military have funded their activities through profits from the mining industry for decades, through both legal and illegal routes (7). In 2017, the military seized control of the mining areas in Kachin from the KIA, and soon after, a UN Human Rights Council fact-finding mission reported on the violations of international human rights law and international humanitarian law perpetrated by the military in these areas (8). These events have led recent media reports to describe working on Myanmar amber as an 'ethical minefield', and to question the 'human cost' of working on this material $(3,4,9)$.

Many countries have legislation in place to protect fossils from being exported illegally, or studied without the involvement of local researchers, a practice that has roots in scientific colonialism (10,11). While Myanmar has a number of national laws that could apply to fossil material in amber (Table 1), the domestic regulation of this material's export has a major loophole(Stewens, 2021). Most of the amber mined in Kachin is sent across the Chinese border to Tengchong, where it is sold in large markets to jewellers, private collectors, and palaeontologists (4). Permanent export of fossil material from Myanmar is prohibited under the 2015 Protection and Preservation of Antique Objects Law. The 1970 UNESCO Convention on the Means of Prohibiting and Preventing the Illicit Import, Export and Transfer of Ownership of Cultural Property (12), an international treaty that entered into force for Myanmar in 2013, also protects cultural property from illicit trafficking (Table 1). However, under the 2019 Myanmar Gemstone Law (and its previous versions) amber is classified as a gemstone and its export can be legal if accompanied with the appropriate paperwork (Table 1). Neither the antiquities law nor the gemstone law explicitly mention amber with fossil inclusions, leading to it falling within a legal grey zone, where the gemstone can in principle be legally exported (with accompanying documentation), but not its fossilised contents.

Due to this seemingly complex legal and ethical situation, the palaeontological community has not yet united on a stance towards the issues surrounding Myanmar amber. In 2020, the 
Society of Vertebrate Paleontology (SVP) released a letter to editors of palaeontological journal editors, calling for a hard moratorium on publishing material in Myanmar amber, particularly that acquired after the military took control of the mines in 2017 (13). Responses to these calls have been varied, with some journals declaring support for this move in the form of changes to their editorial policies $(14,15)$, while other palaeontologists have strongly disagreed $(16,17)$. In 2021, SVP released a second letter calling for a hard moratorium on the publication of fossil material in Myanmar amber obtained after the military coup earlier that year, as well as providing guidelines on researching amber material acquired before this date (18).

While there is not yet direct evidence of Myanmar's military generating revenue from amber with fossil inclusions, it is clear that the enforcement of and adherence to national laws that refer to these specimens is seriously lacking. Numerous publications on spectacularly preserved fossils in Myanmar amber enter the scientific literature each year, and the vast majority of these do not consider the ethical implications of studying this material (10), in particular the links between amber mining in Kachin and the documented human rights abuses by the military. In this study, we use bibliometric and affiliation data from the Web of Science to examine scientometric (publication) trends in Myanmar amber research over the last three decades (1990-2021). We compare these trends to those of publications describing other (non-amber) fossils from Myanmar. Finally, we explore how Myanmar amber research output is related to national and international legal, commercial, and political developments in the country, with the aim of highlighting the need for stronger systemic consideration of the ethical and legal concerns of working on this material, and palaeontological material from other conflict zones around the world.

\section{Results}

Over the past three decades, the number of publications on fossil material in Myanmar amber has generally increased (Fig. 2). Around the year 2014, a breakpoint is observed, dividing the time series into two independent periods: pre-2014 (1990-2013) where the increase in publications on Myanmar amber is slow but steady, and post-2014 (2014-2020) where there is a significantly more dramatic increase (Fig. 2, Table S1). During the first period, pre-2014, the number of publications remained low, but still increased over time $($ slope $=0.55)$, with a peak observed around 2005. This changed after the year 2014 when the number of publications started rapidly increasing (slope $=24.8$ ), reaching its highest value in 2020, with a total of 175 recorded publications in that year alone. The number of publications at the time of writing this manuscript (December 2021) was 129 for the year 2021, indicating that this is unlikely to surpass the 2020 total.

As a comparison, we examined the temporal trends in publications on non-amber fossils from Myanmar, such as Cenozoic primates and petrified wood $(19,20)$. We observed two breakpoints in the non-amber time series, around the years 2004 and 2016. The first publication on body fossils appears in the year 1999, and we see a slow increase over time (slope $=0.25$ ) until 2004 when the number of publications starts decreasing at a similar rate (slope $=-0.35)$ as the previous period (Fig. S1). We see an increase in the number of publications post-2016 (slope $=1.03$ ), although in general, the number of publications on non-amber fossils from Myanmar remained quite low overall, particularly when compared with the number of those on amber fossils. Given the number of publications during this time, the identified breakpoints may not be meaningful in this case.

Most of the palaeontological research on fossils from Myanmar ( 95\%) is based on specimens in amber (Fig. 3), with China being a top contributor, followed by the US (Fig. 3). A considerable amount of research is also contributed by European-based authors, especially from Germany, the UK, France, and Poland. Only 3 publications out of 872 amber publications included researchers from Myanmar on the author list. In contrast, for non-amber publications, the contributions of authors based in Japan $(n=18)$, Myanmar $(n=17)$ and the US $(n=16)$ were very comparable. The number of amber publications post-2014 was 35 times higher than the number of non-amber publications, whereas pre-2014, they were only 5 times higher than nonamber ones. In general, the number of amber publications per country (based on author affiliations) was significantly higher (Wilcoxon test: $V=232, p<0.05$ ) than non-amber publications even after correcting for the expected difference between amber fossils and other fossils (standardised according to the period 2004-2015). No difference between amber and non-amber publications was observed before 2014 (Wilcoxon test: $V=191, p$-value $>0.05$ ).

Examining the network of collaborations between authors on amber and non-amber publications, we identified the countries with considerable power and influence over research trends. Until 2014, researchers from the US were leading in terms of first-authored amber publications $(59 \%, n=69)$ and held the most important position and influence when it came to collaborations, with mostly in-country collaborations occurring during that time (81\%, Fig. 4). Since 2014, China has been the dominant country for Myanmar amber research $(46 \%, n=342)$ with the US moving to second position (10\%, $n=75$, Fig. 4, S2). China did not even find itself in the top ten countries with lead authorship before 2014 (Fig. S2). Multi-author amber publications were also more common post-2014, with only $10 \%(n=76)$ of publications containing a single author after 2014 , compared to $36 \%(n=43)$ before 2014 .

In-country collaborations (i.e. papers published by authors all affiliated with institutions in the same country) were more prevalent before 2014, with an average of $63 \%$ of collaborations being among researchers from the same country, compared with $46 \%$ after 2014. Other countries besides China and the US, such as Germany, Russia and Poland, also significantly contributed to amber research post-2014 (Fig. S3). 


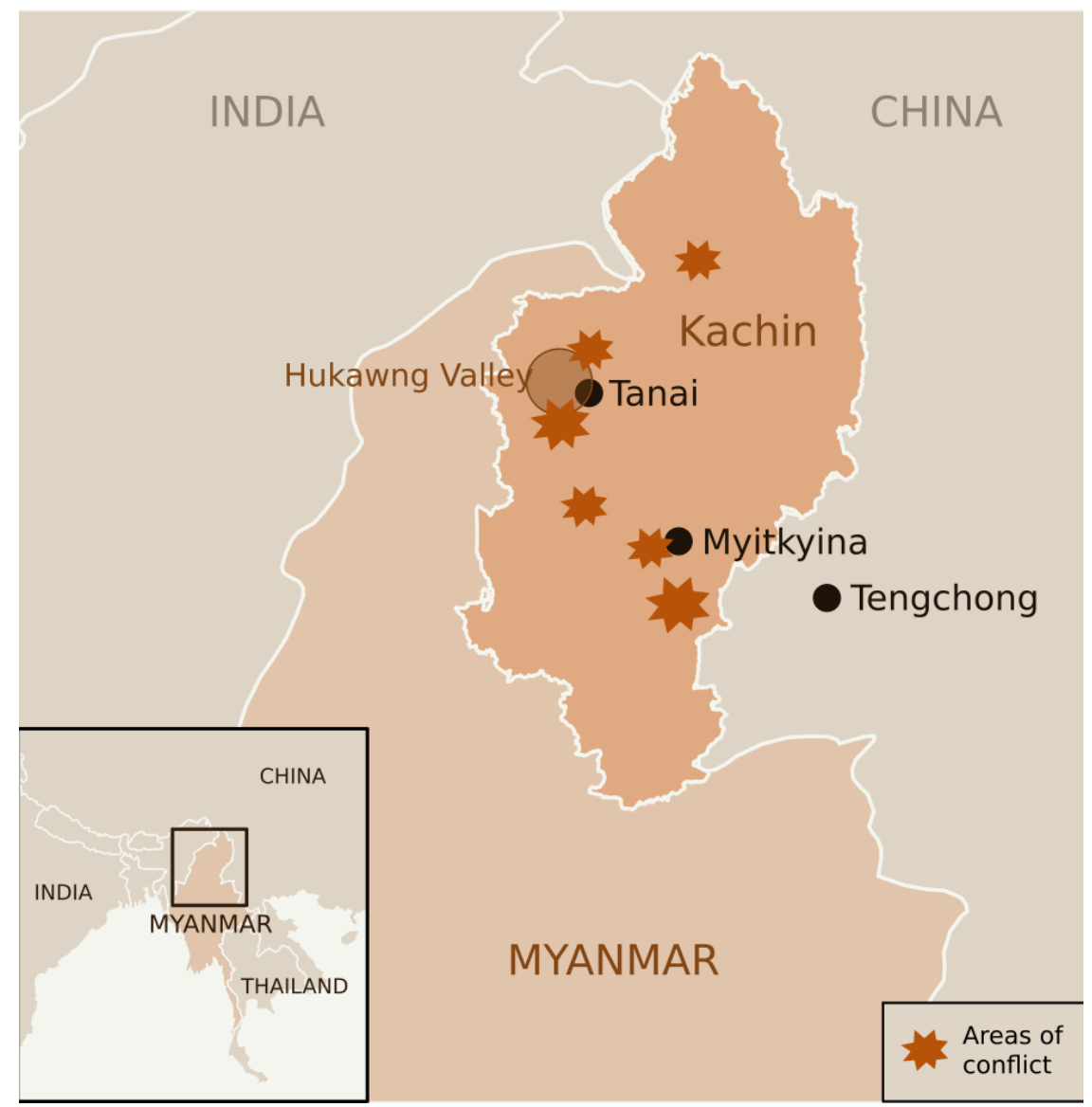

Fig. 1. Location of Myanmar in Southeast Asia (inset) and location of Kachin state in Northern Myanmar (main). Many amber mines are located in Hukawng Valley (circled), close to the city of Tanai. Also included are the major amber trading cities of Myitkyina in Myanmar and Tengchong in Yunnan, China. Star icons denote major areas where conflict (e.g. armed clashes and violence against civilians) has been reported in July 2020 to December 2021 (sourced from The Armed Conflict Location \& Event Data Project; www.acleddata.com)

$$
250-
$$

\section{4}

Jade sales drop

Opening of the Gems and

Jewellery Trade Centre in Myitkyina

$$
200-
$$

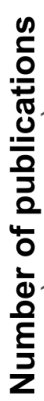
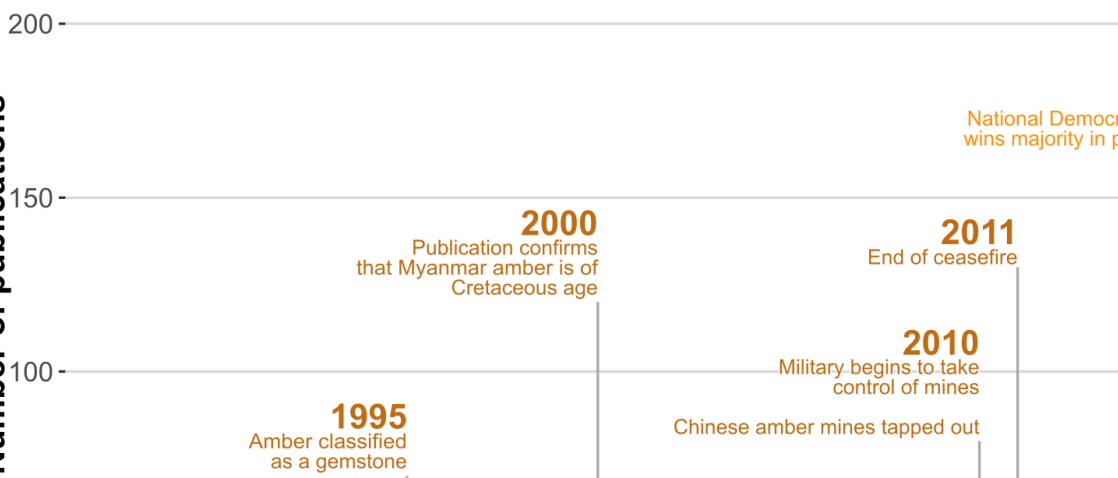


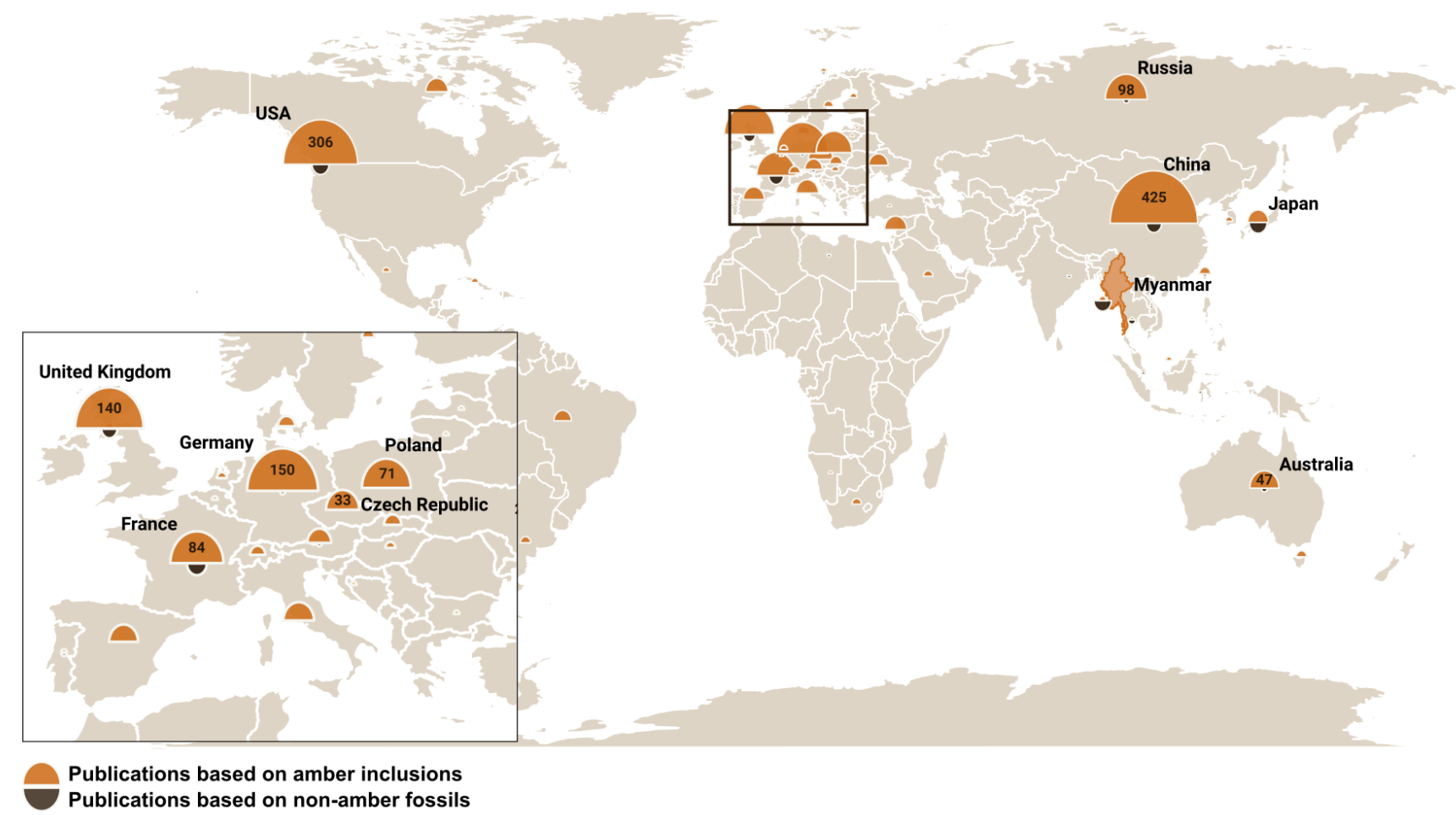

Fig. 3. World countries affiliated with authors who have conducted research on Myanmar amber (orange semi-circles) and non-amber fossils from Myanmar (brown semicircles) from 2014-2021 when the number of publications on Myanmar amber was rapidly increasing year on year. An expanded view of the countries of Europe is shown in the inset.

However, when the collaboration network is analysed regardless of authorship order, Germany and the US have the highest betweenness and degree centrality measures both pre- and post-2014 suggesting that these two countries had a high degree of influence on information flow. China has the highest eigenvalue centrality post-2014, providing evidence for its overall influence in amber research (Fig S4).

\section{Discussion}

Political, legal, and economic factors drive research on Myanmar amber. The dramatic increase in Myanmar amber research output observed over the last years (Fig. 2) can be explicitly linked to major political, legal, and economic changes in the last three decades. Prior to the 2000s, only one publication on Myanmar amber was noted: a paper from 1996, which described fossilised ant specimens housed at the Natural History Museum in London that were acquired during colonial times(Dlussky, 1996). At the same time, the Kachin mining business was undergoing a radical change. Prior to 1994, mines in Kachin were under total control of the Kachin Independence Army (KIA). After a ceasefire agreement with the Tatmadaw, most mining areas in Kachin were nationalised and placed under the control of the state-owned Myanmar Gem Enterprise that regulated mining activity and issued licenses (7, 21). In 1995, a new legislation exclusively for gemstones, including amber, was introduced, allowing their extraction and marketisation (Table 1). In 1999, a Canadian mining company obtained amber pieces from former miners for radiometric dating purposes that were even- tually sent to colleagues at the American Museum of Natural History (AMNH) (22, 23), kickstarting research on Myanmar amber leading to the patterns that we observe today (Fig. 2). Myanmar amber, previously thought to be of Eocene age, was eventually confirmed to be Cretaceous of age around the same time (24). More amber was sold to the AMNH and some private collectors $(25,26)$, which resulted in several publications in the early 2000s (Fig. 2), mostly by researchers based in the US (Fig. 4). During this time, mining operations remained small-scale $(23,26)$.

In the late 2000s and early 2010s, trade with China began to gain momentum, and at the same time, Chinese amber mines tapped out. Consequently, demand for Myanmar amber increased, leading to an expansion of mining operations in the Hukawng Valley $(21,26)$. In 2011, fighting resumed between the KIA and the Tatmadaw-however, seemingly without affecting amber trade with China, which kept growing even in post-ceasefire years (26). Reports seem to suggest that the mining and trade were controlled by a commonality of interest of the Tatmadaw and the KIA, where the KIA controlled the mines but the Tatmadaw regulated the different nodes of trade between Kachin and China $(21,26)$. Both armies collected taxes on the mines and the transportation of amber and related materials (such as fuel, machinery, and food). As the fighting between the KIA and the Tatmadaw got worse between 2014 and 2016, the KIA was driven away from jade and gold mines that they controlled, and amber revenues became even more important. 
(a)

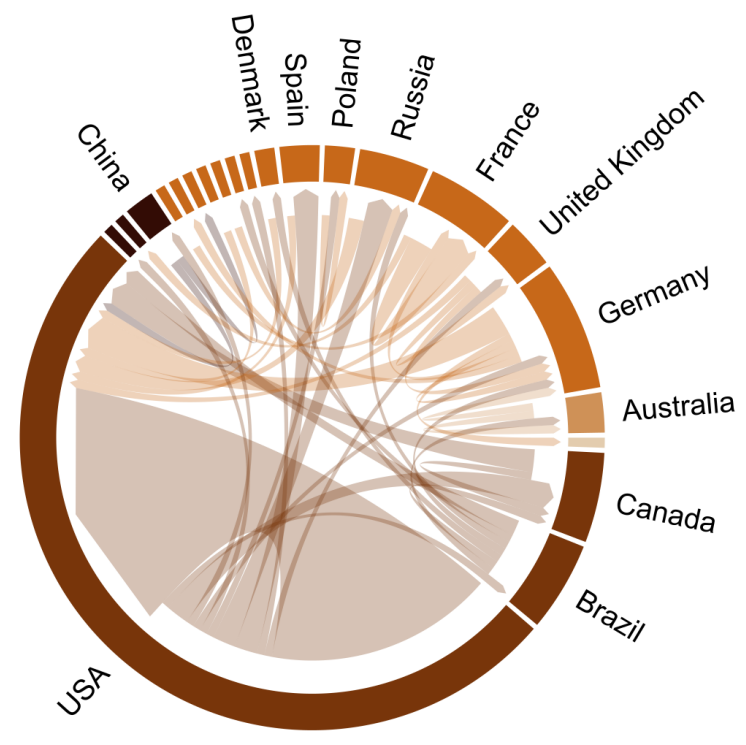

(b)

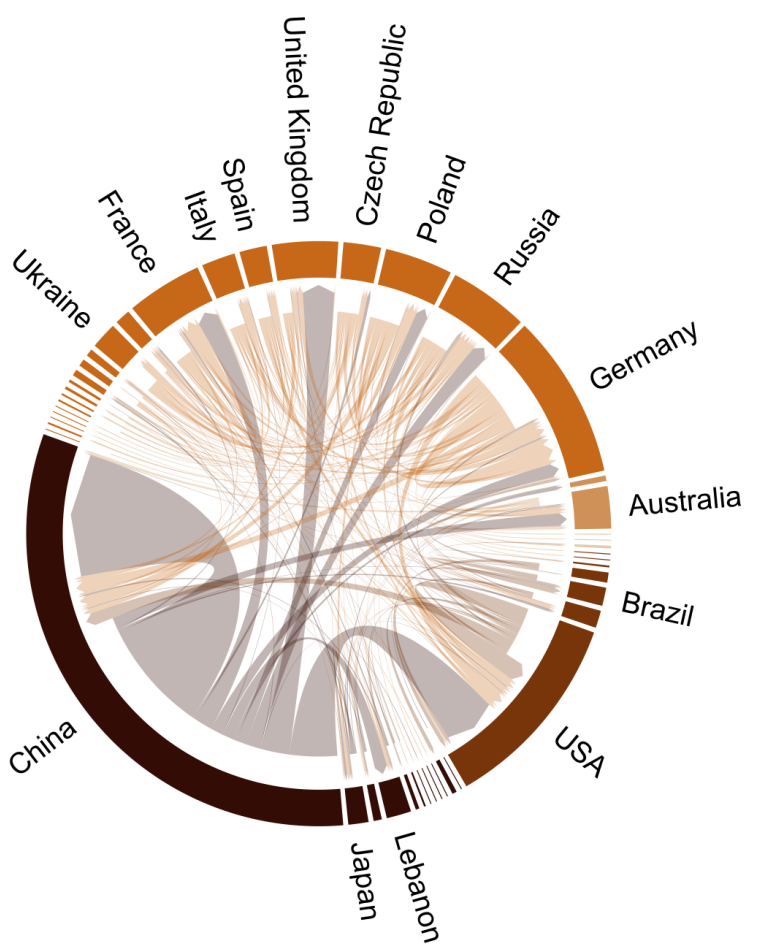

Fig. 4. Relationship networks among countries, coloured by region, showing the "research destinations" of researchers in paleontology. The chords represent connections between the country of authors' institutional affiliations and the country the fossil material has been collected from. The size of each country's circle represents the number of publications on foreign fossil material, also represented by the number of outgoing chords. The countries labelled in bold represent countries with more than 30 outgoing chords, i.e. the most popular "research destinations".

The year 2014 marked the beginning of a dramatic increase in Myanmar amber research output (Fig. 2). This increase correlates with the increased availability of amber, particularly on the Chinese market. Much of the amber mined in Kachin that is taken across the border to be sold in the markets of Tengchong, China, is outside of Myanmar's regulatory landscape, as the cost of custom tax was not deemed to be profitable for traders (26). Once in Tengchong, amber can be legally sold on the Chinese market and is subject to state regulations. Amber can also be bought from the city of Myitkyina in Myanmar, especially at the Gems and Jewellery Trade Centre that opened in 2014 (27). However, this tends to be a less lucrative option for Chinese dealers as amber prices tend to be higher here than across the border in Tengchong.

Amber trade post-2014 was fuelled by the decrease in demand for jade as result of China's economic slowdown and the anti-corruption campaign led by the Chinese government in 2016 (7, 28, 29). Decreasing demand for jade correlated with a subsequent increase in amber in Tengchong (26). As amber became more available on the Chinese market, the material became more accessible to Chinese palaeontologists and private collectors. This likely led to the increase in Myanmar amber publications from 2014 onwards (Fig. 2). Prior to 2014, US researchers dominated research output, whereas after 2014, Chinese researchers have a monopoly (Fig. 4). In both intervals, pre-2014 and post2014, many countries in Europe, such as the UK, Germany, France, Poland, and Russia, as well as Australia and Brazil, retained a share of the research output on Myanmar amber (Fig. 4). This is likely due to their legacy of expertise on the topic of both Myanmar amber and amber from other regions (e.g. Baltic amber). Several of these countries dominate research output on non-amber fossils from Myanmar (Fig. 3), which is related to their general positions as locations of power and knowledge in the field of palaeontology more broadly (10).

The total number of publications on Myanmar amber for 2021 (129 at the time of writing in December 2021) is set to not surpass the 2020 total. This might indicate the beginning of a change in publishing trends and a diminished interest in Myanmar amber research, perhaps due to increased scrutiny from the palaeontological community. Alternatively, this could be a result of knock-on effects from the COVID19 global pandemic, which have both impacted the scientific publishing process and restricted international travel.

Palaeontological research and collaboration in Myanmar. While the post-2014 boom in amber trade increased accessibility of fossil specimens to Chinese researchers, and by extension, to international researchers, it failed to do so for local Myanmar palaeontologists (Fig. 3, 4). The development of the research landscape in Myanmar goes hand in hand with the political changes that have occurred in the country since independence from the United Kingdom in 1948 (30). Until the coup in 1962 that marked the beginning of the political dominance of the military in the country, post- 
colonial Myanmar experienced a boom in university admissions and the government was making various investments in the academic sector (31). Following the 1962 coup, universities lost autonomy over their budgets, and tighter restrictions were put in place on research and travel by Myanmar scholars as well as foreign academics (30). Such restricting and isolationist policies remained in place, curbing research and academic exchange among scholars, until political reforms in the late 2000s and early 2010s, in the lead up to 2015 democratic elections. This is reflected in the research output by Myanmar researchers, which remained low until the early 2010s (Fig. S5), and also in the palaeontological research of non-amber fossils found in the country during that time (Fig. S1).

In Myanmar, international research collaborations are vital for strengthening palaeontological research, and scientific research more broadly, and so it is critical that these international partnerships are equitable and sustainable (32). The Eocene-age Podaung Formation in Myanmar, which contains fossils of the oldest representatives of anthropoid primates (the taxonomic group that includes monkeys, apes, and humans), has been the focus of several field efforts in the last century. The first fossils were collected there in 1914, but no further work occurred until the late 1990s (6, 33). Given the attention that such fossils from Myanmar and other Asian regions were getting at the time, the government organised a fieldwork expedition to the Podaung Formation in 1997, aiming to "enhance the stature of the country" (34). In the following years, joint fieldwork expeditions took place between Myanmar research teams and teams from the US, Japan, and France. Many of these international collaborations persist to this day, resulting in several publications over the years (e.g. $(5,6)$ ). Many of these publications on primate (i.e. nonamber) fossils list researchers from Myanmar as co-authors, which is in stark contrast to amber publications that rarely indicate collaborations with local researchers (Fig. 3).

Only three out of 872 publications on Myanmar amber in our dataset include researchers based in Myanmar as co-authors (Fig. 3). For two of these co-authored publications, the authors listed as being affiliated with an institution in Myanmar, have Chinese institutions as their primary affiliations. Their Myanmar affiliations are listed as the Southeast Asia Biodiversity Research Institute in Myanmar, which was established by the Chinese Academy of Sciences and the Myanmar Ministry of Natural Resources and Environmental Conservation in 2013 through bilateral agreements with the aim of carrying out collaborative research and providing training to young people in South East Asia (35). The third publication talks about the issue of parachute science-where researchers, usually from high income countries, carry out field research, generally in a lower income country without the involvement of local scientists $(10,11,36)$-with respect to Myanmar amber research (32). What we observed here is an extreme form of parachute science where instead of fieldwork, amber specimens are obtained through commercial routes and are apparently not regulated accordingly by national laws relating to fossils or gemstones (Table 1). As such, the mechanisms driving Myanmar amber research are distinct from those leading to other palaeontological work that conforms to national legislations and promotes collaboration between Myanmar and foreign researchers.

\section{Legal and ethical considerations for Myanmar amber} research. The large amount of amber that is moved across the Chinese border to be sold to jewellers, collectors, and palaeontologists indicates that Myanmar's enforcement of its national laws and the UNESCO Convention is seriously deficient (37). However, the current Myanmar amber economy also strongly relies on China, and China, too, is a party to the 1970 UNESCO Convention and the 1995 UNIDROIT Convention (see Table 1). As such, China has an international legal obligation to prevent illicit trafficking of cultural objects, which is likely being violated while tons of amber are smuggled into the country. In countries such as Brazil, Argentina, and Mongolia, where national laws concerning the export and study of fossil specimens are enforced, a greater proportion of palaeontological knowledge is domestically produced $(10,11)$.

Scientific publications describing fossil specimens in Myanmar amber rarely, if ever, provide evidence that their material was obtained legally. Since the letter released by the Society of Vertebrate Paleontology (SVP) in April 2020 calling for a moratorium on publishing Myanmar amber specimens (13), the legal issues associated with Myanmar amber have been even more prominent. Despite this, only 3 out of 174 publications (i.e. less than 1\%) released since this date refer to legal or ethical issues associated with the material they describe (Table S3). Among these, only one (38) provided a detailed description of how the fossil was ethically acquired and accessioned, which was in line with guidelines set out by the Society for Vertebrate Paleontology (13). As mentioned previously, these guidelines have since been updated to include the significance of the recent military coup, as well as steps that should be taken by researchers, journal editors, and peer reviewers when handling publications on Myanmar amber material (18).

Numerous recent media reports have described Myanmar amber as an 'ethical minefield' and note the 'human cost' of working on this material $(3,4,9)$. In the lead-up to the complete takeover of the mines by the Tatmadaw in 2017, several attacks were launched in the amber mining regions, displacing thousands of people, who lost their homes and livelihood (21). While the government claimed that its actions were to protect the environment, the aim may have been to completely control the mining operations given the everincreasing demand and popularity of amber, especially when a dinosaur tail preserved in amber was found and published at the end of 2016 (Fig. S1). The United Nations condemned the military offensive, and a UN fact-finding mission reported violations of international human rights law and international humanitarian law in Kachin, including forced labour, torture, abductions, and sexual violence (8). Amber continues to be mined in hazardous and dangerous conditions, as a result of both the nature of the mine shafts and the continuing conflict 
in the region $(39,40)$. According to recent reports, illegal mining for amber (as well as gold and jade) in Kachin State by groups affiliated with the military has intensified since the coup in early 2021, which has led the UN to suspend climate work with the Myanmar government due to increased pollution from this activity (41). As of August 2021, the state of emergency declared following this year's military coup is set to remain in place until at least August 2023 (42).

Other reports say that there is no evidence that the military generates any significant revenue from amber (43). However, given that most of the amber trade within China occurs within a shadow economy where amber revenues go largely undeclared (26), it is difficult to estimate the revenue the military or other parties have received through the amber trade. However, it is clear that amber smuggling across the Chinese border to Tengchong has directly or indirectly funded both the Tatmadaw and the KIA $(21,26)$.

\section{Conclusions}

The case of fossil material in Myanmar amber is a clear example of exploitative research in palaeontology, centered around the principles of 'parachute science' and scientific colonialism. Our findings document a direct link between political, legal, and economic changes happening within the country and Myanmar amber research output. The situation surrounding Myanmar amber is complex and ever-evolving, but nonetheless shows how scientific research does not happen in a vacuum, and is regularly affected by several, interconnected external factors. For the field of palaeontology, this case highlights the importance of conducting and promoting ethical, equitable, and sustainable research practices. Researchers must also take time to become familiar with the regulatory and cultural landscape of the location where they intend to conduct field research to avoid conduct that is unethical and/or illegal. International collaborations should always include local researchers, who can provide unparalleled insights, even beyond scientific expertise (10,11). Additionally, funders, societies, editors, and peer reviewers must remain vigilant about ethical and legal issues in paleontology to avoid perpetuating exploitative research practices and scientific colonialism. Palaeontology, and the geosciences more broadly, are currently grappling with overdue conversations around the societal and economic impact of their research practices, and action is urgently required. No matter how tenable the link between the scientific work and reported violations, our understanding of ancient life and its evolution should never come at the expense of human rights and human lives.

\section{Materials and Methods}

Data. Bibliometric details of palaeontological publications on Myanmar were downloaded from the Web of Science on the 20th of July, 2021. Publications on Myanmar amber (amber publications, $n=872$ ) and Myanmar fossils not found in amber (non-amber publications, $n=50$ ) were queried separately using specific keywords and filtered for categories pertaining to palaeontology (Table S2). The publications for which affiliations data were missing were manually obtained from the publisher's webpage or from archived version of the manuscript reposited on servers such as ResearchGate or Academia.edu. Only 3 publications, all amber related ones, still had missing affiliations.

Temporal trends in publications. We calculated a 3-year rolling mean of the number of both amber and non-amber publications during the period 1990-2020 to take into account the publication process from acquiring the material to carrying out the analyses to publication in a peer-reviewed journal. The 2021 datapoint was omitted as it only represents the number of publications for half of the year of 2021. A segmented regression with breakpoints analysis was performed on the time series of mean number of publications to identify the years where the temporal patterns in publication significantly changed using the R package segmented v1.3.4 (44). The segmented() function identifies potential breakpoints and calculates one or more segmented relationships from a linear model. This is achieved through an iterative process that only requires the initial values for the potential breakpoint(s) (45). The initial values were obtained based on a visual inspection of the time series as well as the Davies test (46). The Davies test is an independent test which verifies whether a non-constant regression parameter exists in a linear prediction, i.e. whether there is a significant change in slope between k number of points. The Davies test was repeated on identified segmented regressions until no more breakpoints were statistically deemed to be present. The Davies test also returns the best estimate among the k points, which was then fed into the segmented() function which calculates the actual breakpoint using a maximum likelihood algorithm. After this analysis, the study period was divided into the identified segmented periods based on the detected breakpoints. These breakpoints were then compared to changes that occurred in the economic and political situation in Myanmar to identify probable causes for the shifts observed in the palaeontological research landscape.

Amber vs non-amber publications. Because non-amber fossils are without any doubt subject to legislation with regards to collection and export, we consider non-amber publications to be the control group that represents how these materials would be researched if the special circumstances under which amber material fall under would not exist. Given the disproportionate amount of amber publications to nonamber publications (likely a results of the increased availability of amber specimens), we standardised the number of amber publications according to a ratio of amber vs non-amber publications calculated over a certain period of time, identified by the segmented regression analysis. We then compared the standardised number of amber publications to the number of non-amber publications using a Wilcoxon signed-rank test.

Position and influence in amber research. We also investigated the influence that certain countries hold over others when it comes to collaborating on publications about 
Myanmar amber during the segmented periods identified by the breakpoint analysis. We consider lead authorship to be a representation of influence in this particular study as usually for any publication, the lead author (and by extension, their institution or affiliate country) has the most responsibility and power over the line of research within the scope of the publication. As such we looked only at collaborations between the first author and the co-authors on a publication to identify the nature of the relationship between the countries of these authors. A country (country A) is considered to be hold more influence over another country (country B) when the number of publications led by researchers from country A is greater than the number of publications led by country B. We also constructed an undirected collaborative network using all affiliate countries regardless of their position on the authorship list to identify important actors within the network. We use centrality measures such as betweenness centrality and degree centrality as indicators of power. We also looked at whether more in-country collaborations occurred than between countries. Finally, we examined if there were certain countries that stood out in terms of number of leading publications through outlier detection using box plots as per Tukey's method (47).

\section{ACKNOWLEDGEMENTS}

We sincerely thank Professor Khin Zaw for providing invaluable comments on a previous version of this manuscript. Paul Stewens generously assisted with the legal documentation cited here and provided critical perspectives from the field of international law. We also thank Franz Anthony, Daniel Combs, Sarah Greene, Leyla Seyfullah, and Donna Yates, for insightful discussions. E.M.D was supported by a Leverhulme Research Project Grant (RPG-2019-365). N.B.R was supported by the Deutsche Forschungsgemeinschaft (KI 806/17-1) as part of the Research Unit TERSANE (FOR 2332).

\section{AUTHOR CONTRIBUTIONS}

E.M.D. and N.B.R. conceived and designed the project, curated the data, conducted the analyses, prepared figures, and led the writing of the manuscript. P.S. collated and reviewed the legal documentation referenced in the manuscript. All authors (E.M.D, N.B.R, P.S, Z.M.M.T) contributed to the writing and approval of the final manuscript.

\section{DATA AVAILABILITY STATEMENT}

Data and code for the analyses will be made available upon the publication of the peer-reviewed version of this manuscript.

\section{References}

1. Conrad Labandeira, James D. Schiffbauer, and Simon A. F. Darroch. Reading and Writing of the Fossil Record: Preservational Pathways to Exceptional Fossilization. The Paleon tological Society Papers, 20:163-216, October 2014. ISSN 1089-3326, 2399-7575. doi: 10.1017/S108933260000276X. Publisher: Cambridge University Press.

2. Guanghai Shi, David A. Grimaldi, George E. Harlow, Jing Wang, Jun Wang, Mengchu Yang, Weiyan Lei, Qiuli Li, and Xianhua Li. Age constraint on Burmese amber based on U-Pb dating of zircons. Cretaceous Research, 37:155-163, October 2012. ISSN 0195-6671. doi: 10.1016/j.cretres.2012.03.014

3. Katherine Gammon. The Amber-Fossil Supply Chain Has a Dark Human Cost. The Atlantic, 2019.

4. Joshua Sokol. Troubled Treasure: Fossils in Burmese amber offer an exquisite view of dinosaur times-and an ethical minefield, May 2019.

5. Zin-Maung-Maung-Thein, Thaung-Htike, Aung Naing Soe, Chit Sein, Maung-Maung, and Masanaru Takai. Chapter 9 Review of the investigation of primate fossils in Myanmar. Geological Society, London, Memoirs, 48(1):185-206, January 2017. ISSN 0435-4052, 2041-4722. doi: 10.1144/M48.9. Publisher: Geological Society of London Section: Articles.

6. Russell L. Ciochon and Gregg F. Gunnell. Chronology of primate discoveries in Myanmar: Influences on the anthropoid origins debate. American Journal of Physical An thropology, 119(S35):2-35, 2002. ISSN 1096-8644. doi: 10.1002/ajpa.10175. _eprint: https://onlinelibrary.wiley.com/doi/pdf/10.1002/ajpa.10175.

7. Daniel Combs. Until the world shatters: truth, lies, and the looting of Myanmar. Melville House, Brooklyn, 2021. ISBN 978-1-61219-887-3. KerkoCite.ItemAlsoKnownAs: 2664561:7KNWX9FB 2664561:SG7AJ2QW.
8. United Nations. The economic interests of the Myanmar military: Independent International Fact-Finding Mission on Myanmar. UN Doc. A/HRC/42/CRP.3. Technical report, September 2019.

9. Katie Hunt. Amber fossils offer a window into dinosaur times but pose ethical dilemmas. CNN, 2020

10. Nussaïbah B. Raja, Emma M. Dunne, Aviwe Matiwane, Tasnuva Ming Khan, Paulina S. Nätscher, Aline M. Ghilardi, and Devapriya Chattopadhyay. Colonial history and global economics distort our understanding of deep-time biodiversity. Nature Ecology \& Evolution, pages 1-10, December 2021. ISSN 2397-334X. doi: 10.1038/s41559-021-01608-8. Bandiera_abtest: a Cg_type: Nature Research Journals Primary_atype: Research Publisher: Nature Publishing Group Subject_term: Geography;History;Palaeontology;Science, technology and society Subject_term_id: geography;history;palaeontology;sciencetechnology-and-society.

11. Juan C. Cisneros, Aline M. Ghilardi, Nussaïbah B. Raja, and Paul P. Stewens. The moral and legal imperative to return illegally exported fossils. Nature Ecology \& Evolution, pages 1-2, November 2021. ISSN 2397-334X. doi: 10.1038/s41559-021-01588-9. Bandiera_abtest: a Cg_type: Nature Research Journals Primary_atype: Correspondence Publisher: Nature Publishing Group Subject_term: Ethics;Law;Palaeontology Subject_term_id: ethics;law;palaeontology.

12. United Nations. Convention on the Means of Prohibiting and Preventing the Illicit Import, Export and Transfer of Ownership of Cultural Property. Technical report, 1970.

13. Emily Rayfield, R., Jessica Theodor, M., and P. David Polly. Society of Vertebrate Paleontology: Fossils from conflict zones and reproducibility of fossil-based scientific data., April 2020.

14. Acta Palaeontologica Polonica. Burmese Amber and Human Rights. Acta Palaeontologica Polonica: News, 2020.

15. Paul M. Barrett and Zerina Johanson. Myanmar amber fossils: a legal as well as ethica quagmire. Nature, 586(7831):674-674, October 2020. doi: 10.1038/d41586-020-03006-9. Bandiera_abtest: a Cg_type: Correspondence Number: 7831 Publisher: Nature Publishing Group Subject term: Palaeontology, Politics, Publishing.

16. Joachim T. Haug, Dany Azar, Andrew Ross, Jacek Szwedo, Bo Wang, Antonio Arillo, Vikto Baranov, Julia Bechteler, Rolf Beutel, Vladimir Blagoderov, Xavier Delclòs, Jason Dunlop, Kathrin Feldberg, Rodney Feldmann, Christian Foth, René H. B. Fraaije, Alexander Gehler, Danilo Harms, Lars Hedenäs, Matúš Hyžný, John W. M. Jagt, Elena A. Jagt-Yazykova, Ed Jarzembowski, Hans Kerp, Phyo Kay Khine, Alexander G. Kirejtshuk, Christian Klug, Dmitry S. Kopylov, Ulrich Kotthoff, Jürgen Kriwet, Ryan C. McKellar, André Nel, Christian Neumann, Alexander Nützel, Enrique Peñalver, Vincent Perrichot, Anna Pint, Eugenio Ragazzi, Ledis Regalado, Mike Reich, Jouko Rikkinen, Eva-Maria Sadowski, Alexander R. Schmidt, Harald Schneider, Frederick R. Schram, Günter Schweigert, Paul Selden, Leyla J. Seyfullah, Mónica M. Solórzano-Kraemer, Jeffrey D. Stilwell, Barry W. M. van Bakel, Francisco J. Vega, Yongdong Wang, Lida Xing, and Carolin Haug. Comment on the letter of the Society of Vertebrate Paleontology (SVP) dated April 21, 2020 regarding "Fossils from conflict zones and reproducibility of fossil-based scientific data": Myanmar amber. Paläontologische Zeitschrift, 94(3):431-437, September 2020. ISSN 0031-0220, 1867-6812. doi: 10.1007/s12542-020-00524-9. KerkoCite.ItemAlsoKnownAs: 2664561:BEW8V3G9 2664561:GNN6CP4L.

17. Carolin Haug, Jelle W. F. Reumer, Joachim T. Haug, Antonio Arillo, Denis Audo, Dany Azar, Viktor Baranov, Rolf Beutel, Sylvain Charbonnier, Rodney Feldmann, Christian Foth, René H. B. Fraaije, Peter Frenzel, Rok Gašparič, Dale E. Greenwalt, Danilo Harms, Matúš Hyžný, John W. M. Jagt, Elena A. Jagt-Yazykova, Ed Jarzembowski, Hans Kerp, Alexander G. Kirejtshuk, Christian Klug, Dmitry S. Kopylov, Ulrich Kotthoff, Jürgen Kriwet, Lutz Kunzmann, Ryan C. McKellar, André Nel, Christian Neumann, Alexander Nützel, Vincent Perrichot, Anna Pint, Oliver Rauhut, Jörg W. Schneider, Frederick R. Schram, Günter Schweigert, Paul Selden, Jacek Szwedo, Barry W. M. van Bakel, Timo van Eldijk, Francisco J. Vega, Bo Wang, Yongdong Wang, Lida Xing, and Mike Reich. Comment on the letter of the Society of Vertebrate Paleontology (SVP) dated April 21, 2020 regarding "Fossils from conflict zones and reproducibility of fossil-based scientific data": the importance of private collections. PalZ, 94(3):413-429, September 2020. ISSN 1867-6812. doi: 10.1007/s12542-020-00522-x.

18. Jessica Theodor, M., Margaret Lewis, E., and Emily Rayfield, J. Amber specimens acquired from Myanmar following military coup. Society of Vertebrate Paleontology, 2021.

19. Jean-Jacques Jaeger, Olivier Chavasseau, Vincent Lazzari, Aung Naing Soe, Chit Sein, Anne Le Maître, Hla Shwe, and Yaowalak Chaimanee. New Eocene primate from Myanmar shares dental characters with African Eocene crown anthropoids. $\mathrm{Na}$ ture Communications, 10(1):3531, August 2019. ISSN 2041-1723. doi: 10.1038/ s41467-019-11295-6. Bandiera_abtest: a Cc_license_type: cc_by Cg_type: Nature Research Journals Number: 1 Primary atype: Research Publisher: Nature Publishing Group Subject_term: Biogeography;Biological anthropology;Palaeontology;Taxonomy Subject_term_id: biogeography;biological-anthropology;palaeontology;taxonomy.

20. Alexis Licht, Anaïs Boura, Dario De Franceschi, Torsten Utescher, Chit Sein, and JeanJacques Jaeger. Late middle Eocene fossil wood of Myanmar: Implications for the landscape and the climate of the Eocene Bengal Bay. Review of Palaeobotany and Palynology, 216:44-54, May 2015. ISSN 0034-6667. doi: 10.1016/j.revpalbo.2015.01.010.

21. Kachin Development Networking Group. Blood Amber Military resource grab clears out indigenous peoples in Kachin State's Hugawng Valley. Technical report, Kachin, 2019

22. R. D Cruickshank and Ko Ko. Geology of an amber locality in the Hukawng Valley, Northern Myanmar. Journal of Asian Earth Sciences, 21(5):441-455, February 2003. ISSN 13679120. doi: 10.1016/S1367-9120(02)00044-5.

23. David A. Grimaldi, Michael S. Engel, and Paul C. Nascimbene. Fossiliferous Cretaceous Amber from Myanmar (Burma): Its Rediscovery, Biotic Diversity, and Paleontological Significance. American Museum Novitates, 2002(3361):1-71, March 2002. ISSN 0003-0082, 1937-352X. doi: 10.1206/0003-0082(2002)361<0001:FCAFMB>2.0.CO;2. Publisher: American Museum of Natural History.

24. V. V. Zherikhin and AJ Ross. A review of the history, geology and age of Burmese amber burmite. Bulletin of the Natural History Museum Geology Series, 20(1):3-10, 2000.

25. Livius Drusus. The 100-Million-Year-Old Spider Attack Captured in Amber. Mental Floss, 
April 2015. Section: Animals.

26. Alessandro Rippa and Yi Yang. The Amber Road: Cross-Border Trade and the Regulation of the Burmite Market in Tengchong, Yunnan. TRaNS: Trans-Regional and -National Studies of Southeast Asia, 5(2):243-267, July 2017. ISSN 2051-364X, 2051-3658. doi: 10.1017/trn.2017.7. Publisher: Cambridge University Press KerkoCite.ItemAlsoKnownAs: 2664561:7GWGAWXV 2664561:D838HNAU.

27. Tin Htet Paing. The Amber Hub of Myitkyina. The Irrawaddy, 2017.

28. Chan Mya Htwe. Jade traders call for open market as sales reach new lows. The Myanmar Times, March 2016

29. Hlaing Kyaw Soe. Traders swap jade for amber. The Myanmar Times, May 2016.

30. Zu Xian (Anders) Lee, Jana Rue Glutting, Naing Lin Htet, Ngu Wah Win, Nyein Chan Aung, Thaint Zar Chi Oo, and Zaw Oo. Doing Research in Myanmar: Country Report. Technical report, Center for Economic and Social Development., June 2020. Accepted: 2020-0817T02:15:52Z ISBN: 9788194595014 Publisher: Center for Economic and Social Development.

31. Maung Maung. Pyidawtha Comes to Burma. Far Eastern Survey, 22(9):117-119, 1953 ISSN 0362-8949. doi: 10.2307/3023996. Publisher: [University of California Press, Institute of Pacific Relations].

32. Zin-Maung-Maung-Thein and Khin Zaw. Parachute research is another ethical problem for Myanmar amber. Nature Ecology \& Evolution, 5(6):707-707, June 2021. ISSN 2397-334X. doi: 10.1038/s41559-021-01472-6. Bandiera_abtest: a Cg_type: Nature Research Journals Number: 6 Primary_atype: Correspondence Publisher: Nature Publishing Group Subject term: Evolutionary ecology;Palaeontology Subject term id: evolutionary-ecology:palaeontology KerkoCite.ItemAlsoKnownAs: 2664561.FX6ZXLJP 2664561:I4A9Y99X 2664561:RJDXJFKR

33. Khin Zaw, Sebastien Meffre, Masanaru Takai, Hisashi Suzuki, Clive Burrett, Thaung Htike, Zin Maung Maung Thein, Takehisa Tsubamoto, Naoko Egi, and Maung Maung. The oldest anthropoid primates in SE Asia: Evidence from LA-ICP-MS U-Pb zircon age in the Late Middle Eocene Pondaung Formation, Myanmar. Gondwana Research, 26(1):122-131, July 2014. ISSN 1342-937X. doi: 10.1016/j.gr.2013.04.007.

34. Than Tun. Formation of the Pondaung Fossils Expedition Team and report on the work accomplished. Proceedings of the Pondaung Fossils Expedition Team. Yangon: Office of Strategic Studies, Ministry of Defence. p, pages 1-16, 1999.

35. Na Chen. China-Myanmar Established Biodiversity Research Institute Unveiled in Nay Pyi Taw. Chinese Academy of Sciences, 2016.

36. Paris V. Stefanoudis, Wilfredo Y. Licuanan, Tiffany H. Morrison, Sheena Talma, Joeli Veitayaki, and Lucy C. Woodall. Turning the tide of parachute science. Current Biology, 31(4):R184-R185, February 2021. ISSN 0960-9822. doi: 10.1016/j.cub.2021.01.029.

37. Paul Philipp Stewens. Burmese Amber: Palaeontology's Blood Diamonds Through the Lens of International Law. Völkerrechtsblog, page 24.06.2021, June 2021. doi: 10.17176/ 20210624-192927-0. Publisher: Fachinformationsdienst für internationale und interdisziplinäre Rechtsforschung.

38. Juan D. Daza, Edward L. Stanley, Arnau Bolet, Aaron M. Bauer, J. Salvador Arias, Andrej Čerňanský, Joseph J. Bevitt, Philipp Wagner, and Susan E. Evans. Enigmatic amphibians in mid-Cretaceous amber were chameleon-like ballistic feeders. Science, 370(6517):687691, November 2020. doi: 10.1126/science.abb6005. Publisher: American Association for the Advancement of Science.

39. Nan Lwin Hnin Pwint. Displaced by Clashes Over Amber, Villagers in Myanmar's Kachin State Risk Death to Secretly Mine It. The Irrawaddy, 2019.

40. Lawi Weng. Miners Flee Conflict in Kachin State. The Irrawaddy, June 2017.

41. Thin Lei Win. UN suspends climate work with Myanmar government following military coup. Climate Home News, 2021. Section: Asia.

42. Reuters. Myanmar army ruler takes prime minister role, again pledges elections. Reuters, August 2021.

43. George Poinar and Sieghard Ellenberger. Burmese Amber Fossils, Mining, Sales and Profits. Geoconservation Research, 3(1), April 2020. doi: 10.30486/gcr.2020.1900981.1018. KerkoCite.ItemAlsoKnownAs: 2664561:6BVDV2ZD 2664561:93XVU6ZD.

44. Vito M. R. Muggeo. Interval estimation for the breakpoint in segmented regression: a smoothed score-based approach. Australian \& New Zealand Journal of Statistics, 59:311322, 2017. doi: 10.1111/anzs.12200.

45. Vito M. R. Muggeo. Estimating regression models with unknown break-points. Statistics in Medicine, 22(19):3055-3071, 2003. ISSN 1097-0258. doi: 10.1002/sim.1545. _eprint: https://onlinelibrary.wiley.com/doi/pdf/10.1002/sim.1545.

46. Robert B. Davies. Hypothesis testing when a nuisance parameter is present only under the alternative: Linear model case. Biometrika, 89(2):484-489, June 2002. ISSN 0006-3444. doi: 10.1093/biomet/89.2.484

47. John W Tukey. Exploratory data analysis, volume 2. Reading, Mass., 1977.

\section{Legal Documents}

\section{International Treaties.}

- Convention for the Protection of Cultural Property in the Event of Armed Conflict (adopted 14 May 1954, entered into force 7 August 1956), 249 UNTS 215.

- Convention on the Means of Prohibiting and Preventing the Illicit Import, Export and Transfer of Ownership of Cultural Property (adopted 14 November 1970, entered into force 24 April 1972), 823 UNTS 231.

- UNIDROIT Convention on Stolen or Illegally Ex- ported Cultural Objects (adopted 24 June 1995, entered into force 1 July 1998), 2421 UNTS 457.

\section{Domestic Legislation.}

- The Myanmar Gemstone Law 1995 (The State Law and Order Restoration Council Law No. 8/95)

- The Law Amending the Myanmar Gemstone Law 2003 (The State Peace and Development Council Law No. 8/2003)

- Second Amendment to the Myanmar Gemstone Law 2016 (Pyidaungsu Hluttaw Law No. 23/2016)

- The Myanmar Gemstone Law 2019 (Pyidaungsu Hluttaw Law No. 4/2019)

- The Antiquities Act 1957

- The Protection and Preservation of Antique Objects Law 2015 (Pyidaungsu Hluttaw Law No. 43/2015) 
Table 1. National laws and international treaties that apply to fossil specimens in amber uncovered in Myanmar. The national laws listed below can be accessed through Myanmar Law Library (myanmar-law-library.org).

\begin{tabular}{|c|c|c|}
\hline \multicolumn{2}{|l|}{ Laws and treaties } & Description \\
\hline \multirow[t]{4}{*}{ National legislation on gemstones } & 1995 Myanmar Gemstone Law & $\begin{array}{l}\text { Classifies amber as a gemstone and } \\
\text { outlines the permits and permis- } \\
\text { sions required to excavate and sell } \\
\text { gemstones (including amber) both } \\
\text { nationally and internationally. }\end{array}$ \\
\hline & $\begin{array}{l}2003 \text { First Amending Law of the } \\
\text { Myanmar Gemstone Law (1995) }\end{array}$ & $\begin{array}{l}\text { Includes minor changes to wording } \\
\text { of the original } 1995 \text { law }\end{array}$ \\
\hline & $\begin{array}{l}2016 \text { Second Amending Law of the } \\
\text { Myanmar Gemstone Law (1995) }\end{array}$ & $\begin{array}{l}\text { Builds on the original } 1995 \text { law } \\
\text { and generally allows for larger scale } \\
\text { production of gemstones. Also } \\
\text { states that gemstones (including } \\
\text { amber) must be sold internation- } \\
\text { ally in accordance with trade regu- } \\
\text { lations in border towns permitted by } \\
\text { the Myanmar Ministry of Mines. }\end{array}$ \\
\hline & 2019 Myanmar Gemstone Law & $\begin{array}{l}\text { No official English translation pub- } \\
\text { licly available as of December } 2021\end{array}$ \\
\hline \multirow[t]{2}{*}{ National legislation on antiquities } & 1957 Antiquities Act & $\begin{array}{l}\text { States that antiquities (which in- } \\
\text { cludes "any fossil remains of man } \\
\text { or of animal") are not to be exca- } \\
\text { vated without permission from the } \\
\text { then Director of the Burma Archae- } \\
\text { ological Survey. Any antiquities } \\
\text { that are discovered must be imme- } \\
\text { diately reported to the director, and } \\
\text { export of antiquities is not permis- } \\
\text { sible without prior permission. }\end{array}$ \\
\hline & $\begin{array}{l}2015 \text { The Protection and Preserva- } \\
\text { tion of Antique Objects Law }\end{array}$ & $\begin{array}{l}\text { Defines antique objects as "tangible } \\
\text { and intangible cultural heritage in- } \\
\text { cluding fossil, corpse and bones of } \\
\text { human beings and various types of } \\
\text { animals". Permission to carry out } \\
\text { excavations must be sought from } \\
\text { the Department of Archaeology and } \\
\text { National Museum. Transport of an- } \\
\text { tiquities to foreign countries with- } \\
\text { out permission can result in impris- } \\
\text { onment and/or fines. }\end{array}$ \\
\hline International treaties & $\begin{array}{l}1954 \text { Hague Convention for the } \\
\text { Protection of Cultural Property in } \\
\text { the Event of Armed Conflict with } \\
\text { Regulations for the Execution of the } \\
\text { Convention }\end{array}$ & $\begin{array}{l}\text { Entered into force for Myanmar in } \\
1956 \text {, its article } 4(3) \text { requires con- } \\
\text { tracting states "to prohibit, prevent } \\
\text { and, if necessary, put a stop to any } \\
\text { form of theft, pillage or misappro- } \\
\text { priation of [...] cultural property" in } \\
\text { the event of an armed conflict. }\end{array}$ \\
\hline
\end{tabular}


1970 UNESCO Convention on the Means of Prohibiting and Preventing the Illicit Import, Export and Transfer of Ownership of Cultural Property

1995 UNIDROIT Convention on Stolen or Illegally Exported Cultural Objects
Came into force for Myanmar in 2013. This treaty "urges States Parties to take measures to prohibit and prevent the illicit trafficking of cultural property. It provides a common framework for the States Parties on the measures to be taken to prohibit and prevent the import, export and transfer of cultural property."

In force in Myanmar since 2018. This treaty supplements the 1970 UNESCO Convention in regulating the private law implications of the restitution of cultural objects that had been stolen or illegally exported. The agreement inter alia provides that stolen cultural objects must be returned and that good faith purchasers are entitled to compensation. Besides, any state party may request another to return illegally exported cultural objects. 


\title{
Supporting Online Material:
}

\section{Ethics, law, and politics in palaeontological research: The case of Myanmar amber}

\author{
Emma M. Dunne, Nussaïbah B. Raja, Paul Stewens \& Zin Maung Maung Thein
}

\begin{abstract}
This manuscript has not been formally accepted for publication and is as such a nonpeer reviewed preprint. Subsequent versions of this manuscript may have slightly different content. If accepted in a peer-reviewed journal, the final version of this manuscript will be available via the Peer-review Publication link on this web-page. Feel free to contact us if you have any queries or comments; we welcome any feedback that you may have.
\end{abstract}

The following section contains:

- Supplementary tables S1-S3

- Supplementary figures S1-S5 
Table S1. Results from Davies' test to identify a change in slope in a linear regression. The test is repeated on the generated segmented regression after a breakpoint is identified (when $p<0.05$ ) until no breakpoints are deemed to be statistically present (when $p>0.05$ ). The column "best at" represents the point in the variable at which the maximum test statistic occurs. The "actual breakpoint" is the breakpoint then identified using a log-likelihood function.

\begin{tabular}{|l|l|l|l|l|}
\hline \multirow{2}{*}{ Publication type } & \multicolumn{3}{|c|}{ Davies test } & \multirow{2}{*}{ Actual breakpoint } \\
\cline { 2 - 5 } & statistic & p-value & best at & \\
\hline \multirow{2}{*}{ Amber } & 21.7 & $6.4 \mathrm{E}-13$ & 2014.8 & 2013.9 \\
\cline { 2 - 5 } & -2.92 & 0.09 & 2019 & NA \\
\hline \multirow{3}{*}{ Non-amber } & 6.42 & $9.71 \mathrm{E}-05$ & 2016.9 & 2016.4 \\
\cline { 2 - 5 } & -3.42 & 0.03 & 2004.2 & 2004.0 \\
\cline { 2 - 5 } & 1.83 & 0.40 & 2006.3 & NA \\
\hline
\end{tabular}

Table S2. Query details for bibliometric data obtained from the Web of Science.

\begin{tabular}{|l|l|l|l|}
\hline $\begin{array}{l}\text { Publication } \\
\text { type }\end{array}$ & Keywords & Categories & Query Link \\
\hline Amber & $\begin{array}{l}\text { 'Myanmar amber' OR 'Kachin am- } \\
\text { ber' OR 'Burmese amber' }\end{array}$ & $\begin{array}{l}\text { Paleontology, Geology, Zoology, } \\
\text { Entomology, Evolutionary Biology }\end{array}$ & $\begin{array}{l}\text { https://www.webofscience.com/wos/ } \\
\text { woscc/summary/398c1e91- } \\
\text { c98f-47fe- ad3c-bf37eab44aed- } \\
\text { a19a8e6d/relevance/1 }\end{array}$ \\
\hline Non-amber & $\begin{array}{l}\text { 'Myanmar AND paleontology'OR } \\
\text { 'Myanmar AND palaeontology' } \\
\text { OR 'Myanmar AND paleobiology' } \\
\text { OR 'Myanmar AND palaeobiol- } \\
\text { ogy' NOT 'amber' }\end{array}$ & $\begin{array}{l}\text { Paleontology, Geology, Zoology, } \\
\text { Entomology, Evolutionary Biology }\end{array}$ & $\begin{array}{l}\text { ht//www.webofscience.com/wos/ } \\
\text { woscc/summary/2a75fa0c-3edc- } \\
\text { 4937- 9823-a530d1e3be22- } \\
0152 \mathrm{a} 0 \mathrm{ec} / \text { relevance/1 }\end{array}$ \\
\hline
\end{tabular}


Table S3. Example ethics declarations used in publications since May 2020 (following the release of a letter by the Society of Vertebrate Paleontology)

\begin{tabular}{|c|c|c|}
\hline Publication & Statement & Position \\
\hline Daza et al. (2020) Science & $\begin{array}{l}\text { "Specimens were acquired following the ethical guide- } \\
\text { lines for the use of Burmese amber set forth by the So- } \\
\text { ciety for Vertebrate Paleontology (see "Provenance and } \\
\text { Ethical Statement" section of the supplementary materi- } \\
\text { als for a detailed description of ethical fossil acquisition } \\
\text { and accession). We hope that this study will serve as a } \\
\text { model for other researchers working with these types of } \\
\text { materials in this region." }\end{array}$ & $\begin{array}{l}\text { Separate section at } \\
\text { end of main text and } \\
\text { in supplementary } \\
\text { material }\end{array}$ \\
\hline Badano et al. (2021) Insects & $\begin{array}{l}\text { "We are aware of the ethical issues involving Burmese } \\
\text { amber and we declare that the specimen was collected } \\
\text { before the humanitarian crisis that started in the exca- } \\
\text { vation areas in } 2017 \text {. The specimen is deposited in the } \\
\text { Nanjing Institute of Geology and Palaeontology (NIGP), } \\
\text { Chinese Academy of Sciences at Nanjing, China, in full } \\
\text { compliance with the recommendations of ICZN, and the } \\
\text { instructions of the International Palaeoentomological So- } \\
\text { ciety. The material examined during the present study } \\
\text { was borrowed from the NIGP with the assurance that it } \\
\text { had been acquired and imported in compliance with all } \\
\text { local procedures and regulations" }\end{array}$ & Methods section \\
\hline Luo et al. (2021) Insects & $\begin{array}{l}\text { "To avoid any confusion and misunderstanding, all au- } \\
\text { thors declare that the fossil reported in this study was not } \\
\text { involved in armed conflict and ethnic strife in Myanmar. } \\
\text { This specimen is deposited permanently in a publicly } \\
\text { owned collection in a national museum, in full compli- } \\
\text { ance with the International Code of Zoological Nomen- } \\
\text { clature and Statement of the International Palaeoentomo- } \\
\text { logical Society" }\end{array}$ & Methods section \\
\hline
\end{tabular}




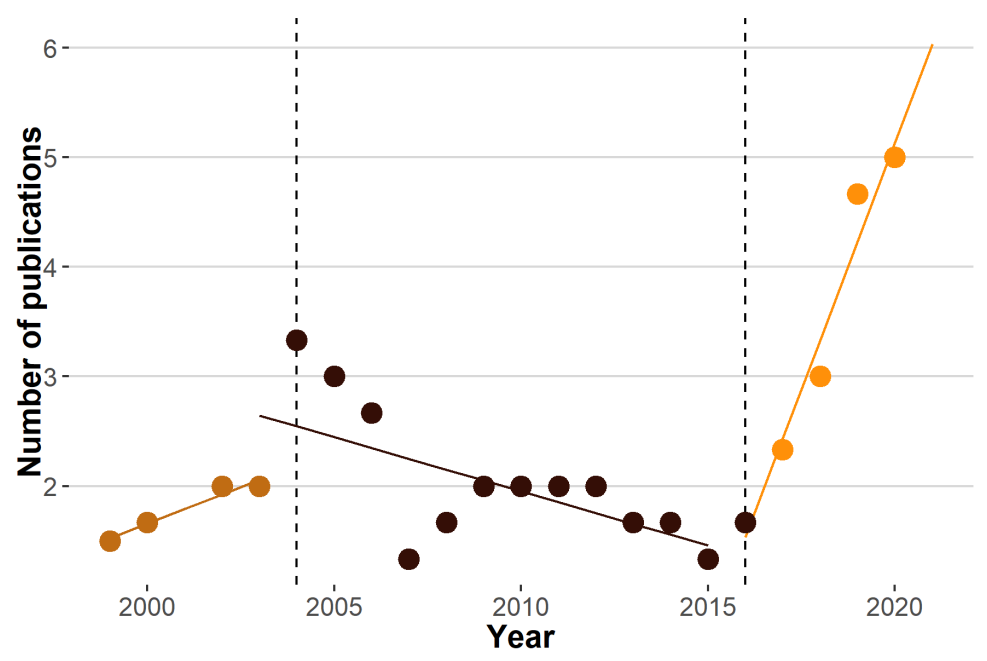

Fig. S1. Trends in Myanmar non-amber publication activity. Breakpoints in the time series are represented by the dotted line.

(a)

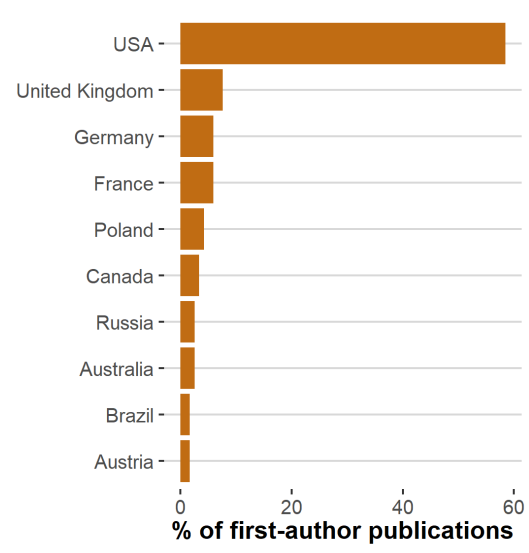

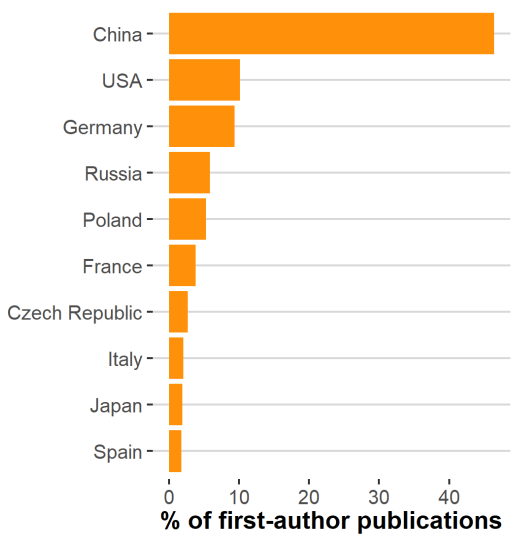

Fig. S2. Percentage of first author publications on amber research for (a) pre-2014 ( $n=118)$, (b) post-2014 $(n=737)$. 

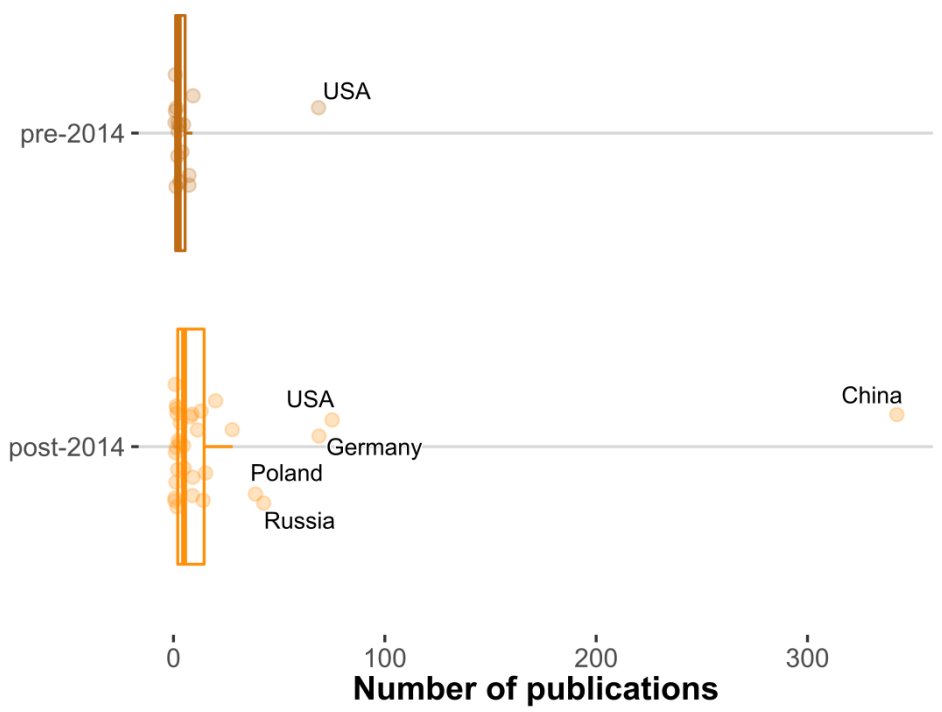

Fig. S3. Distribution of number of publications per country before and after 2014. Each point represents a country that was listed as the affiliate country for the lead author for at least one publication. Countries that had significantly higher numbers of publications (outliers) are labelled.

(a)

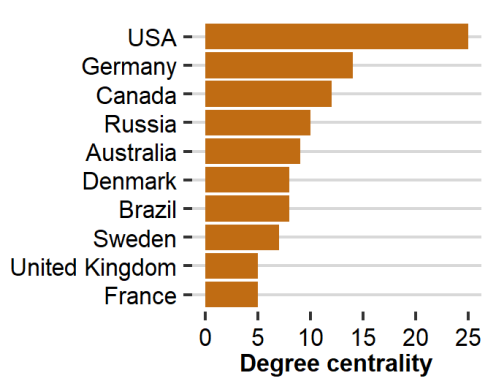

(d)

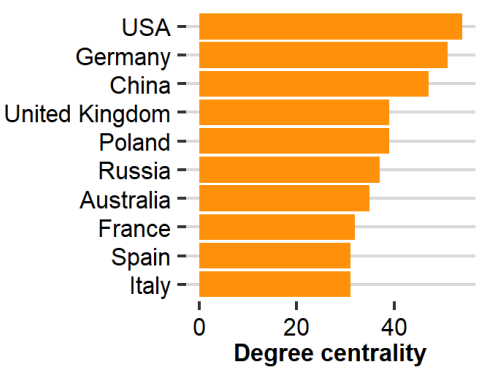

(b)

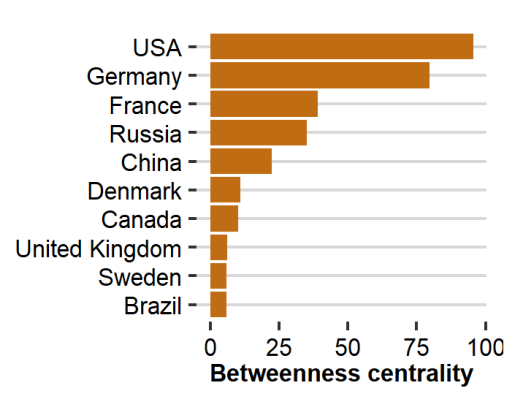

(e)

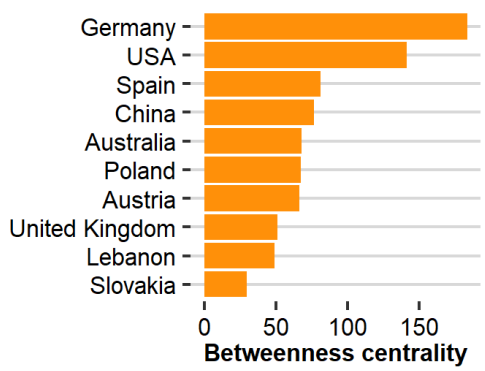

(c)

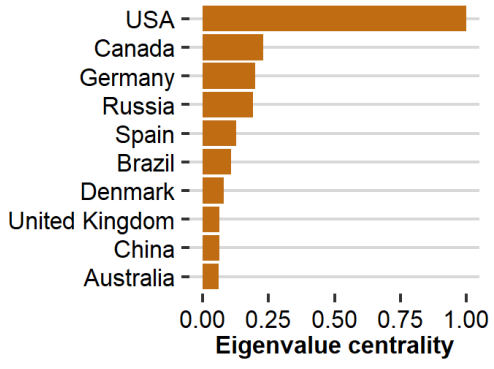

(f)

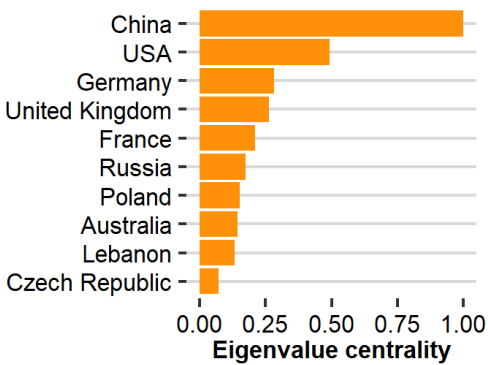

Fig. S4. Centrality measures for (a-c) pre-2014 and (d-f) post-2014. Only the top 10 countries for each measure are shown. 


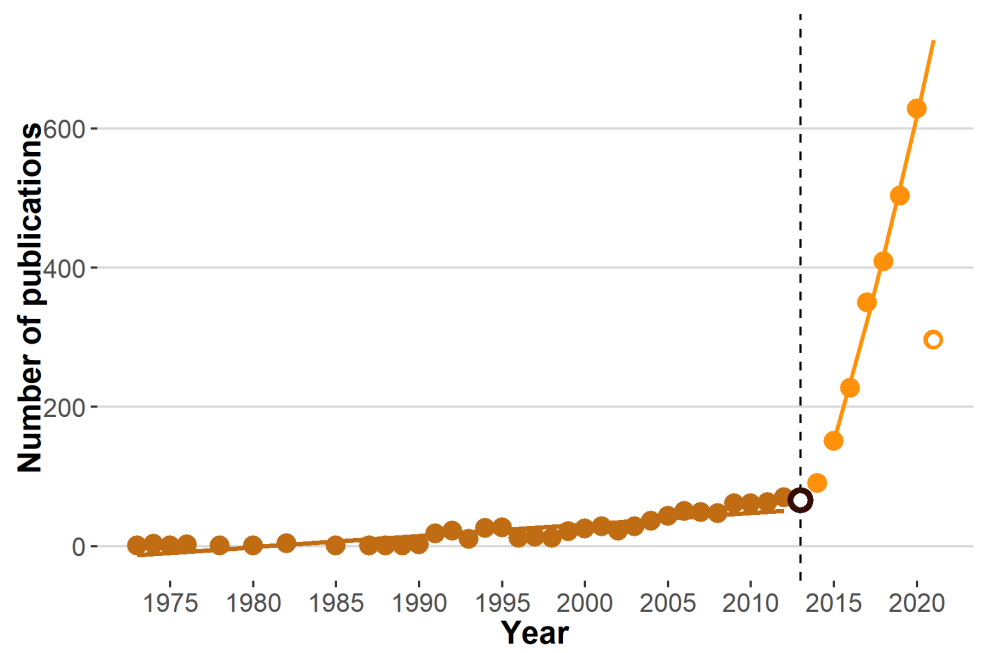

Fig. S5. Trends in publication activity by Myanmar researchers. Breakpoints in the time series are represented by the dotted line. Data obtained from the Web of Science. 